\title{
ANEURISMA MICOTICO DE ORIGEM EXTRA-VASCULAR
}

\author{
Nelson Pires Ferreira " \\ José Leonardo Camino Teixeira **
}

A identificação de aneurismas intracranianos causados por processos infecciosos - aneurismas micóticos - tem sido relatada na literatura em diversas oportunidades ${ }^{1,2,3,6}$. $\mathrm{Na}$ maioria são de etiologia embólica, secundários à endocardite bacteriana, e localizados nos ramos terminais das artérias encefálicas. Recentemente as infecções de origem extra-vascular, na gênese de aneurismas intracranianos, vêm sendo consideradas em relatos eventuais $4,5,7,8$.

A infrequência da patologia e o número restrito de relatos justificam a presente comunicação.

\section{OBSERVAÇAO}

M.L.T., 3 anos, sexo feminino, branca, internada no Instituto de Neurocirurgia de Porto Alegre em 4-3-1975 (Reg. n.o 13.922). Há um mês, aparecimento de tumoração depressivel localizada na região fronto-parietal direita, próxima ao vértex. Dez dias após houve rotura da tumoração com saída de grande quantidade de líquido purulento, havendo cura ulterior. Há 15 dias aparecimento de prurido ocular à direita e, há doze, exoftalmia e queda da pálpebra acompanhadas de imobilidade ocular que permaneceram até a data da internação. Dor ocular à direita, persistente, desde o inicio do quadro clinico. Exame clinico-neurológico: exoftalmia năo pulsátil, sem sopro, e oftalmoplegia completa à direita. A angiografia carotídea mostrou aneurisma da artéria carótida interna em sua porção intra-cavernosa (Fig. 1). Tratamento cirúrgico: ligadura da artéria carótida interna direita, em um tempo, na altura do pescoço. Após a cirurgia houve desaparecimento da dor ocular. No momento da alta hospitalar, sete dias após a intervencão cirúrgica, era possível notar regressão parcial do quadro deficitário neurológico.

\section{COMENTARIOS}

Os aneurismas infecciosos - micóticos - se formam à custa do enfraquecimento da parede arterial motivado pela ação bacteriana. Segundo Blackwood $^{2}$ a parede arterial mostra alterações histológicas de processo inflamatório agudo. Ȧ medida que progride o enfraquecimento das lâminas elás-

Trabalho realizado no Instituto de Neurocirurgia: * Professor Assistente do Departamento de Cirurgia da UFRGS e membro do Instituto de Neurocirurgia; ** Instrutor de Ensino da Disciplina de Neurologia da Faculdade de Medicina da Universidade de Caxias do Sul 
tica e média há dilatação localizada da artéria que pode evoluir até a rotura vascular. Quando de etiologia embólica, localizam-se mais frequentemente nos ramos periféricos das artérias intra-cranianas e são de pequenas dimensões e múltiplos. Os êmbolos sépticos habitualmente procedem das valvas aórticas, no curso de endocardites bacterianas.
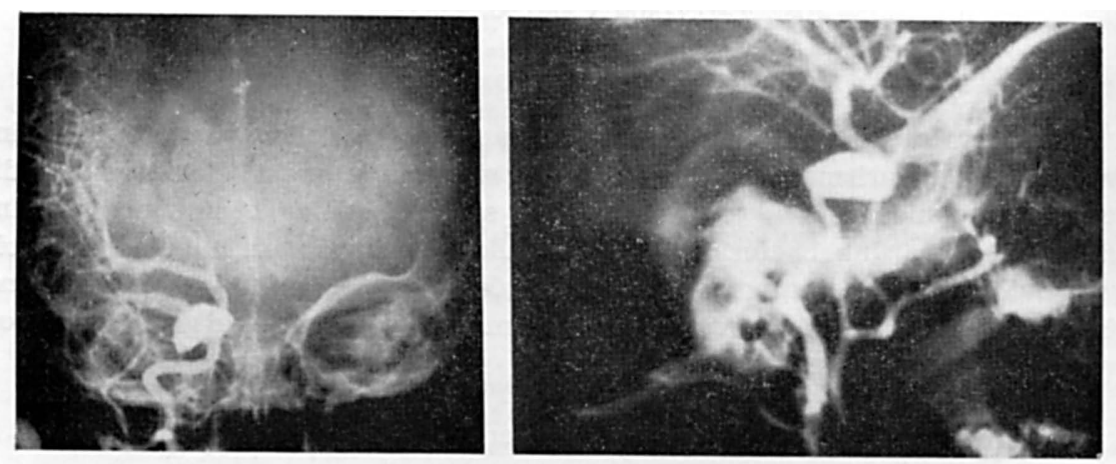

Fig. 1 - Arteriografia nas incidências AP e P mostrando aneurisma da artéria carótida interna em sua porção intra-cavernosa.

Nos últimos anos relatos correlacionam processo infeccioso extra-vascular e dilatações arteriais. Ojeman \& col. ${ }^{7}$ estabelecem, pela primeira vez, relação entre a presença de aneurismas distais e múltiplos de artérias intracranianas com meningite bacteriana aguda. No caso por eles estudado é afastada a etiologia embólica. Davis \& col. ${ }^{4}$, em sua extensa revisão, identificaram, incluindo a sua casuística, seis pacientes portadores de aneurisma da artéria carótida interna em sua porção intra-cavernosa, na sequência de quadro clínico de tromboflebite de seio cavernoso. Esses autores ${ }^{4}$ acreditam que os aneurismas estudados foram causados por processo infeccioso do seio cavernoso que desencadeou arterite de origem extra-vascular. A evolução desses aneurismas pode ser: para trombose e cura espontânea ou para dilatação progressiva com ulterior rotura ou calcificação da parede. Devadig \& col. ${ }^{5}$ e Suwanwele \& col. ${ }^{8}$ observaram cura espontânea em alguns de seus casos. O último trabalho refere a persistência do aneurisma, com calcificação da parede, em duas oportunidades.

O caso aqui relatado pode ser classificado como aneurisma infeccioso micótico -, secundário à tromboflebite de seio cavernoso. A ligadura da artéria carótida interna no pescoço foi escolhida como tratamento, na espectativa de resolução da compressão intra-cavernosa dos nervos oculomotores e da correção da dor ocular persistente. No momento da alta hospitalar a dor havia desaparecido, sendo identificada a regressão parcial da deficiência neurológica. 


\section{RESUMO}

E relatado o caso de uma paciente com três anos de idade portadora de oftalmoplegia completa unilateral e aneurisma da artéria carótida interna, em sua porção intra-cavernosa. A etiologia infecciosa extra-vascular, na vigência de tromboflebite de seio cavernoso, foi considerada. As informações da literatura são discutidas, sendo comentada a infrequência da patologia. A indicação de ligadura da artéria carótida interna, no tratamento desses aneurismas, merece ulterior comprovação.

\section{SUMMARY}

\section{Mycotic aneurysm of extravascular origin: a case report}

The case of a female patient presenting a complete unilateral ophthalmoplegia secundary to a septic aneurysm of the internal carcíid artery is reported. The possible existence of an extravascular infectious etiology in view of the presence of trombophlebitis of the cavernous sinus is discussed. Pertinent reports from the literature are reviewed and the rarity of the phenomenon is commented. The indication for internal carotid artery ligation as a form of treatment deserves further observations.

\section{REFERENCIAS}

1. ALLCOCK, J.M. - Aneurysms. In NEWTON, T.H. \& POTTS, D.G. - Radiology of the Skull and Brain-Angiography. The C.V. Mosby So., Saint Louis, 1974, vol. 2, cap. 82, pp. 2435-2489.

2. BLACKWOOD, W. - Vascular disease of the central nervous system. In BLACKWOOD, W.; MCMENEMEY, W.H.; MEYER, A.; NOEMAN, R.M. \& RUSSELL, D.R. — Greenfield's Neuropathology. 2nd ed. Edward Arnold Ltd., London, 1963, cap. 2, pp. 71-137.

3. CANTU, R.C.; MARJORIE, L. \& WILKINSON, H.A. - The importance of repeated angiography in the treatment of mycotic-embolic intracranial aneurysms. J. Neurosurg. 25:189, 1966.

4. DAVIS, D.O.; DILENGE, D. \& SCHLAEPFER, W. - Arterial dilatation in purulent meningitis: a case report. J. Neurosurg. 32:112, 1970.

5. DEVADIGA, K.V.; MATHAI, K.V.E. \& CHANDY, J. - Spontaneous cure of intracavernous aneurysm of the internal carotid artery in a 14-month-old child. J. Neurosurg. 30:165, 1969.

6. HEIDRICH, R. - Subarachnoid haemorrhage. In VINKEN, P.J. \& BRUYN, G.W. - Handbook of Clinical Neurology. Vascular Disease of the Nervous System, Part II. North-Holland Pub. Co., Amsterdam, 1972, vol. 12, cap. 5, pp. 68-204.

7. OJEMANN, R.G.; NEW, P.F.J. \& FLEMING, T.C. - Intracranial aneurysms associated with bacterial meningitis. Neurology (Minneapolis) 16:1222, 1966.

8. SUWANWELA, C.; SUWANWELA, C.; CHARUCHINDAS, S. \& HOGSAPRABHAS, C. - Mycotic aneurysms of extravascular origin. J. Neurosurg. 36:552, 1972.

Instituto de Neurocirurgia de Porto Alegre - Hospital de Neurocirurgia-Santa Casa - 90000 Porto Alegre, RS - Brasil. 